\title{
RATES OF DEMENTIA IN THREE ETHNORACIAL GROUPS
}

\author{
BARRY J. GURLAND ${ }^{1 *}$, DAVID E. WILDER ${ }^{1}$, RAFAEL LANTIGUA ${ }^{1}$, YAAKOV STERN ${ }^{2}$, JIMING CHEN $^{1}$, \\ ELOISE H. P. KILLEFFER ${ }^{1}$ AND RICHARD MAYEUX ${ }^{2}$ \\ ${ }^{1}$ Columbia University Stroud Center, Faculty of Medicine and the New York State Psychiatric Institute, \\ New York, USA \\ ${ }^{2}$ Gertrude H. Sergievsky Center, Columbia University, USA
}

\begin{abstract}
Background. Rates of dementia may vary among ethnoracial groups. Any real and substantial such difference would merit serious attention by health planners, clinicians and those seeking to advance our understanding of the etiology of this group of disorders.

Methods. Randomly selected elderly persons from each of three ethnoracial groups (Latinos, African-Americans, non-Latino Whites) residing in a geographic area of northern Manhattan in New York City were screened for dementia and assessed with respect to functioning in daily tasks and other qualities of life. Systematic samples of each group were clinically evaluated for presence and subtype of dementia. Subjects were reassessed at an average of 18 months following the baseline interview.

Results. Age-specific prevalence of dementia was found to be higher in Latinos and African-Americans than in nonLatino Whites; incidence rates were consistent with this finding. Ethnoracial groups did not vary in the proportion of dementias diagnosed as Alzheimer's disease. Prevalence differences between ethnoracial groups remained consistent as diagnostic criteria were varied in breadth and when the possible mislabelling of depression was taken into account. However, level of education was strongly associated with rates of dementia and, when age and education were simultaneously controlled, the ethnoracial differences in rates were not consistently found.

Conclusions. Planning for the wide range of services necessary for care of those suffering from dementia should take into account ethnoracial differences in rates. The higher rates found in Latino and African-American groups, relative to non-Latino Whites, are associated with clear and substantial functional dependencies and hence have important implications for qualities of life and service needs. Copyright (C) 1999 John Wiley \& Sons, Ltd.
\end{abstract}

KEY WORDS - ethnoracial; Latinos; African-Americans; functioning; qualities of life; prevalence; dementia; incidence; education; service

\section{BACKGROUND}

\section{Relative rates of dementia}

Rates of dementia in elder populations are reported to vary among ethnoracial groups, whether based on clinical diagnosis, algorithms or threshold scores on cognitive scales. In community surveys, several studies have reported higher rates of dementia among AfricanAmericans or Latinos than among non-Latino

*Correspondence: Dr Barry Gurland, Stroud Center, 100 Haven Avenue 29F, New York, NY 10032.

Contract grant sponsor: Federal Grants.

Contract grant number: AG07232, AG10489.

Contract grant sponsor: The Morris W. Stroud III, Programme on Scientific Approaches to Quality of Life and Aging, Endowment Fund.
Whites (Schoenberg et al., 1985; Weissman et al., 1985; Escobar et al., 1986; Murden et al., 1991; Heyman et al., 1991). Subtype variation has also been noted, with higher rates of vascular subtypes of dementia in African-Americans than in nonLatino Whites (Folstein et al., 1991; Heyman et al., 1991) and, in an autopsy series (de la Monte et al., 1989), higher rates of dementia associated with Parkinson's disease in non-Latino Whites than in African-Americans, while the latter had the higher rates of dementia associated with multi-infarct disease and alcoholism.

Any substantial real differences in rates of dementia between ethnoracial groups merit serious public health, clinical and etiological attention. For example, the ethnoracial composition of the nation's population of elders will undergo sharp 
transformation over the next 50 years, with the Latino elder population growing tenfold and the African-American population threefold, while the non-Latino white population will only double (Day, 1996). Projections of rates of dementia would need to take these demographic changes into account.

Nevertheless, relative differences among ethnoracial groups may arise from influences that transcend ethnoracial characteristics. In particular, elders who have had low education are consistently reported as having unusually high rates of dementia (Gurland, 1981; Li, 1991; Folstein et al., 1991; Stern et al., 1994; Gurland et al., 1995; Bachman et al., 1989; Zhang et al., 1990). Less educated groups have also been reported to have a greater proportion of multi-infarct dementia (Folstein et al., 1991) or increased rates of alcoholic dementia and unspecified types of dementia (Fratiglioni et al., 1991).

\section{Absolute rates of dementia}

A review of population-based prevalence studies prior to the mid-1980s found a median prevalence of $5.2 \%$ in five European studies and $6.5 \%$ in four US studies (Cross and Gurland, 1986). Reports of prevalence averaged about $1 \%$ at age $65-74,7 \%$ at age $75-84$ and $25 \%$ in those aged 85 years or over. Jorm et al. (1987), in a quantitative meta-analysis of prevalence studies during the period 1945-1985, came to quite similar conclusions: that prevalence was around $2 \%$ at age $65,8 \%$ at ages $75-84$ and $30 \%$ over age 84 . These two reviews were generally consistent with other reviews of that time (eg Gunner-Svensson and Jensen, 1976; Kay, 1977). However, there is marked variation among studies (by a factor of as much as 2 or more) in the agespecific rates.

We have located an additional 16 studies published since 1985 (references in Appendix) that employ clinical diagnoses based on the DSM-III/IV (American Psychiatric Association, 1987, 1994) or the NINCDS-ADRDA (McKhann et al., 1994) criteria. As in the pre-1985 set of studies, there is marked variation among studies. Discrepancies between studies in reported rates apply also to subtypes such as Alzheimer's disease or multi-infarct dementia (Folstein et al., 1991). Nevertheless, the median age-specific rates remain congruent with those of the pre-1985 period. The handful of population-based incidence studies (references in Appendix) also show great variability among studies, especially after age 85 years.

Variation in estimates of rates of dementia may hinge upon the definition of a case. The broader or more inclusive the definition, the higher must be the rates. Yet, the choice of case definition may reasonably be tied to the purpose of a study. A clinical view could emphasize the broad inclusion of those cases predicted to follow a dementing course, but yet at a stage early enough for secondary prevention or anticipatory management. Etiological studies might choose a narrower case definition in order to obtain maximal homogeneity in the targeted group of cases. From a public health perspective, a relevant breadth of case definition might be one that identifies persons whose condition affects their cognitively driven functional competence.

Absolute prevalence rates are especially pertinent for anticipating national costs of dementia services (Wimo et al., 1997). The economic burden in the United States is already enormous, estimated at $\$ 18000$ per case year in 1983 (Hay and Ernst, 1987) or as high as $\$ 50000$ per case year in California 1988-1990 (Rice et al., 1993). Hay and Ernst use prevalence figures of roughly $5-6 \%$ in the population aged 65 and over, and find overall US costs of around 30 billion dollars (in 1983). Had these investigators employed a higher prevalence rate of dementia, their national cost estimates would have been proportionately greater.

\section{Scope of this article}

Here we derive relative and absolute estimates of prevalence and incidence rates of dementia and its subtypes in three ethnoracial groups of elders living in North Manhattan or admitted to nursing homes from that area. Earlier analyses of these data (Gurland et al., 1995) addressed the influence of case definition on rates and the relevance of diagnostic concepts to public health and clinical concerns. However, at that time, the baseline assessments were available on only a subset of the study cohort and the first follow-up had not yet been carried out.

\section{METHODS}

\section{The North Manhattan Aging Project (NMAP)}

Details of the NMAP methods have been published (Gurland et al., 1992, 1997a); a brief 
summary of the study methods is given here. The NMAP established a registry of cases of dementia, drawing cases from a network of key informants (Reporting Component) and a cohort (Survey Component) or randomly selected persons 65 years or older within a bounded 'target' geographic area of 13 adjacent census tracts in North Manhattan. Poverty, crime and unemployment rates are high in the study target area.

\section{Sample}

The analyses in this report are restricted to the Survey Component and that part of the Reporting Component that covered nursing home residents whose last community residence was in the target area.

In the Survey Component, the sampling frame included all Medicare beneficiaries 65 years or older, within the geographic target area. Subjects in the survey were drawn by random methods in replicated subsamples equally from the three cultural groups till the numbers of elders in any group were exhausted or the total of elders interviewed exceeded 2100. In the first four of 37 representative survey subsamples, all subjects were referred for diagnostic evaluation and an informant, where available, was also interviewed. In the other subsamples, an informant interview and a referral for a research diagnostic evaluation was done only if the threshold score on the cognitive screen was equalled or exceeded, and in a randomly selected quarter of the rest of the subjects. The cognitive screen threshold was set at three or more errors, equal to $90 \%$ sensitivity for diagnosis of dementia in the pilot study. The field interviews were administered by trained raters, usually using laptop computers in face-to-face interviews at the subject's home. Informant interviews were conducted by telephone.

In the Reporting Component, study staff repeatedly scrutinized records of subjects in health and social service sites which have a known high rate of dementia cases, and also received referrals according to specified criteria from key informants in a wide variety of other health, social and community sites. The nursing home residents in the analyses that follow were selected from among those given criterion evaluations in the Reporting Component in 1989-1991. Estimates of the number of nursing home residents over the age of 65 years and admitted from the study area were made based on repeated enumerations of study area nursing homes.

For purposes of calculating prevalence rates, the numerators are the number of cases of dementia identified in the Survey Component at baseline and in the nursing home segment of the Reporting Component over the corresponding length of time (ie 18 months). Case identification of dementia was based on the criterion diagnosis for those subjects who received a diagnostic evaluation, and was projected from those subjects onto persons screened but not diagnosed by means, described below, of (1) a weighting procedure, and (2) an algorithm.

Subsample weights. Weighting for cases defined by criterion diagnosis was adjusted as follows. For the first four survey random subsamples, in which all subjects were referred to diagnosis in the clinical core, no subsample adjustment was necessary; nor for subjects who failed the cognitive screening threshold, because all those were also referred to diagnosis regardless of their subsample membership. In the $25 \%$ random subset of subjects not in the first four subsamples, and who passed the screen but were by design referred to diagnosis, cases were multiplied by four and added to the other prevalent cases. For cases derived from the algorithms, all subjects were classified as dementia or not dementia and no subsample adjustment of the numerator was required.

Non-response weights. Numbers of dementias were inflated by a weight that accounted for nonresponse to diagnostic referral

The resulting subsample and non-response weights combined were respectively: for subsamples 1-4, 1.20754; subsamples 5-37 and screen score $3+, 1.28729$; subsamples $5-37$ and screen score $<3,4.64659$.

The rules for the algorithm are (i) the criterion diagnosis is used; but, if not available on a particular subject, then (ii) apply a discriminant function based on the subject's cognitive score and an informant's report on the subject's competence in daily activities; if informant information is also missing, then (iii) use the subject's own report on their daily activities; if all information on daily activities is missing on a subject, then (iv) enter the cognitive score alone to assign the classification. The kappa coefficient (chance corrected agreement) of the discriminant function (with removal of diagnosis itself from the predictor variables) is 0.60 with criterion diagnosis on subjects who 
received a diagnostic evaluation (true positives 202, true negatives 632, false negatives 68 and false positives 94 ).

The denominators are the numbers of persons interviewed in the community and the nursing home supplement. No adjustments were applied.

\section{Minimizing ethnoracial biases}

Efforts were made to render screening and field classificatory techniques as culture-fair as possible. Interviews were conducted in the language of preference (English or Spanish) of the subject. A Spanish translation of each assessment technique was prepared and checked for comparability with the English version; for a few items, a cultural equivalent rather than a literal translation was chosen.

The choice of the cognitive screen was based on a previous comparison of five alternatives to determine which was most consistent in operational characteristics (eg specificity and sensitivity) across ethnoracial groups (Wilder et al., 1995). The most consistent across ethnoracial groups was the Comprehensive Assessment and Referral Evaluation cognitive screen (Golden et al., 1983; Teresi et al., 1984; Wilder et al., 1995), which was therefore selected as this study's cognitive screen.

A criterion diagnosis was made after detailed evaluation guided by algorithms and operational criteria for integration of information from psychometric tests (with educational norms) and laboratory and clinical findings. This diagnosis was made independently of, and blind to, the field assessments. The initial separation is between demented and non-demented patients. If a patient is demented, then the cause of dementia is specified further. Further details of the diagnostic criteria and procedures are given elsewhere (Stern et al., 1992).

\section{Interview content}

The subject interview in the Survey Component includes a wide range of qualities of life, with particular attention to details of functioning in daily tasks of living. Items from several standard measures of functioning have been embedded in the interview: Katz Index of Activities of Daily Living (Katz et al., 1963), Lawton Instrumental Activities of Daily Living (Lawton and Brody, 1969) and Comprehensive Assessment and Referral Evaluation scales of activity limitation and mobility (Gurland et al., 1977; Golden et al., 1984). A scale of higher-level functioning was abstracted for discriminating cognitive from physical controls of functioning (Wilder et al., 1994). An hierarchical index of severity in affective suffering was developed for these data analyses (Gurland et al., 1997b).

The informant interview covers a range of current functioning of the subject similar to that in the subject interview. Additional items are directed at historical information on the onset and course of the subject's symptoms.

\section{Breadth of diagnostic concept}

We expected that diagnostic misclassifications due to error or bias will be rare for subjects who are obviously demented (ie display the severe cognitive impairment of advanced dementia) or are clearly normal (ie have no evidence of cognitive impairment on testing). Rather, misclassifications are likely to occur mainly on subjects who have borderzone levels of cognitive impairment. Therefore, the designation of a borderzone range of cognitive impairment is expedient for study of ethnoracial variation in rates of dementia. Borderzone nondementia comprises those subjects who are not diagnosed as demented but have evidence of cognitive impairment; and borderzone dementias are those who are diagnosed as demented but whose level of cognitive impairment overlaps with the non-dementias (Wilder et al., 1994, 1995; Gurland et al., 1995).

Scores on the cognitive screening instrument of no errors or one error operationally identify a cognitively normal group of subjects $(N=326)$ with a relatively low diagnosed rate of dementia $(3.4 \%)$; scores of two to five errors demarcate the borderzone cognitively impaired group $(N=494)$ with a dementia rate of $24.3 \%$ (separating into borderzone dementias and borderzone nondementias); and from six to 11 errors defines the advanced cognitively impaired group $(N=169)$ with a dementia rate of $84.4 \%$. Cases are designated 'paradoxical' and are excluded from comparisons of diagnostic breadth if there is a diagnosis of dementia but no evidence of cognitive impairment on the screen $(N=11)$, or if dementia is not diagnosed despite evidence of advanced cognitive impairment on the screen $(N=28)$.

Since rates are partly dependent on the breadth of the concept of dementia employed, for comparisons among ethnoracial groups we will include 
separate reference to borderzone dementias as well as advanced dementias. Advanced dementia typifies a narrow (conservative) view of dementia caseness; a broad concept is represented by expanding the definition to include the borderzone dementias.

\section{Socioeconomic classification}

Elders were assigned to the three ethnoracial groups on the basis of their self-attribution that they were of Spanish/Hispanic origin or descent and, if not, that they were White or Black/Negro. Educational achievement categories are $0-4$ years of school completed, 5-11 years, and 12 or more years. Household income was elicited by asking the subject to select their monthly income bracket from a list displayed on a card. All main sources of income were specifically mentioned, including wages, salaries, social security or retirement benefits, help from relatives and rent from property.

\section{Longitudinal aspects}

Subjects were followed at intervals averaging 18 months. Subject interviews and diagnostic procedures, but not informant interviews, were repeated.

\section{RESULTS}

\section{Yields from the Survey Component}

Of the 5403 subjects in the sample drawn for survey, 470 subjects had died and 896 were no longer in the target area prior to assigning a baseline interview. The addresses on record of a further 538 subjects were located, but their eligibility, continued residence within the target community or their willingness to be interviewed could not be confirmed during the window of time allowed for completion of a given subsample. Fortyseven subjects did not meet eligibility criteria and 1340 declined to be interviewed. Interviews were completed on 2112 eligible subjects who spoke English or Spanish. Fifty nursing home residents were added as previously described, giving a total of 2162 subjects whose data were entered into the analyses. Comparison of the age and gender distributions of the responders and non-responders for each ethnoracial group revealed no significant differences for gender. However, responders in all ethnoracial groups were younger than nonresponders, with the differences rising to statistical significance for Latinos $(p=0.001)$ and nonLatino Whites $(p=0.01)$.

Clinical evaluations were conducted with 1056 of these elder subjects at baseline; of these, 733 not in nursing homes and 11 in nursing homes were clinically evaluated again on average 18 months later. Informants for 966 subjects (not in nursing homes) were interviewed at baseline. Ethnoracial and gender profiles of the study cohort at baseline and first follow-up are shown in Table 1

\section{Relative ethnoracial prevalence rates}

Prevalence of dementia in the three age strata $(65-74,75-84,85+)$ based on the criterion diagnosis is: for Latinos $7.5 \%, 27.9 \%$ and $62.9 \%$; for African-Americans, 9.1\%, 19.9\% and 58.6\%; and for non-Latino Whites, $2.9 \%, 10.9 \%$ and $30.2 \%$. Prevalence rates of dementia defined by the

Table 1. Age and sex distribution of subjects at baseline and first follow-up

\begin{tabular}{lrrrrrr}
\hline & \multicolumn{2}{c}{ Male } & \multicolumn{2}{c}{ Female } & \multicolumn{2}{c}{ Total } \\
& $N$ & $\%$ & $N$ & $\%$ & $N$ & $\%$ \\
\hline Baseline & & & & & & \\
$\quad$ Latino & 306 & 46.5 & 695 & 46.2 & 1001 & 46.3 \\
African-American & 208 & 31.6 & 521 & 34.6 & 729 & 33.7 \\
Non-Latino White & 144 & 21.9 & 288 & 19.1 & 432 & 20.0 \\
$\quad$ Total & 658 & 100.0 & 1504 & 100.0 & 2162 & 100.0 \\
1st follow-up & & & & & & \\
Latino & 206 & 47.6 & 487 & 40.6 & 693 & 49.0 \\
African-American & 133 & 30.7 & 321 & 32.7 & 454 & 32.1 \\
$\quad$ Non-Latino White & 94 & 21.7 & 173 & 17.6 & 267 & 18.9 \\
Total & 433 & 100.0 & 981 & 100.0 & 1414 & 100.0 \\
\hline
\end{tabular}


Table 2. Distribution of subtypes of dementia by ethnoracial group

\begin{tabular}{|c|c|c|c|c|c|c|c|c|}
\hline & \multicolumn{2}{|c|}{ Latino } & \multicolumn{2}{|c|}{ African-American } & \multicolumn{2}{|c|}{ Non-Latino White } & \multicolumn{2}{|c|}{ Total } \\
\hline & $N$ & $\%$ & $N$ & $\%$ & $N$ & $\%$ & $N$ & $\%$ \\
\hline Alzheimer's disease & 143 & 88.3 & 98 & 91.6 & 23 & 92.0 & 264 & 89.8 \\
\hline Uncomplicated & 103 & 63.6 & 62 & 57.9 & 14 & 56.0 & 179 & 60.9 \\
\hline With Parkinson's & 8 & 4.9 & 2 & 1.9 & 1 & 4.0 & 11 & 3.7 \\
\hline With stroke & 22 & 13.6 & 18 & 16.8 & 6 & 24.0 & 46 & 15.6 \\
\hline With other concomitant disease & 10 & 6.2 & 16 & 15.0 & 2 & 8.0 & 28 & 9.5 \\
\hline Other dementias & 19 & 11.7 & 9 & 8.4 & 2 & 8.0 & 30 & 10.2 \\
\hline Stroke-related & 6 & 3.7 & 2 & 1.9 & 0 & 0.0 & 8 & 2.7 \\
\hline By focal effects of stroke & 4 & 2.5 & 1 & 1.0 & 1 & 4.0 & 6 & 2.0 \\
\hline Other or unknown & 9 & 5.6 & 6 & 5.6 & 1 & 4.0 & 16 & 5.4 \\
\hline All other dementias & 162 & 100.0 & 107 & 100.0 & 25 & 100.0 & 294 & 100.0 \\
\hline
\end{tabular}

algorithm are: for Latinos, 9.5\%, 26.0\% and $54.2 \%$ for African-Americans, $9.6 \%, 21.7 \%$ and $47.0 \%$; and for non-Latino Whites, $3.9 \%, 8.6 \%$ and $33.3 \%$.

By either definition of a case, all ethnoracial groups show a steep rise of rates of dementia with age, more than doubling with each age decade. Within age groups, rates are highest in Latinos and African-Americans and lowest in non-Latino Whites. Comparisons made between ethnoracial groups within the three age groupings show that in all age categories, rates for Latino and AfricanAmerican groups are similar. However, the nonLatino White group has significantly lower rates when compared with Latinos in age groups 65-74 $(p<0.05), 75-84 \quad(p<0.01)$ and 85 or over $(p<0.01)$; and relative to African-Americans in age groups $65-74(p<0.01,75-84(p<0.05$ and $85+p<0.01)$.

\section{Determinants of relative prevalence rates}

Differences in prevalence rates between groups can arise variously from differences in incidence, duration and age of onset, mortality, subtype of dementia, or bias in making diagnoses. Incidence findings require the most complex presentation and are therefore presented last.

Mortality. Mortality rates at 18-month followup were examined in relation to dementia (eg algorithmic definition). Odds ratios for increase of mortality in dementias aged $65-74$ were 4.77 for Latinos, 2.94 for African-Americans and 6.70 for non-Latino Whites. The corresponding odds ratios for ages $75-84$ were $1.91,1.23$ and 1.44 ; and for ages 85 and over $0.77,2.83$ and 11.0 , respectively. The greatest effect of dementia on mortality is found in the oldest non-Latino White group.

Age of onset. At the baseline interview we had collected retrospective information from informants $(N=602)$ on the age of onset of functional impairments of the subject. In 110 of these subjects, the impairments were attributed by the informant to dementia; onset after age 84 was reported in $37.5 \%$ of these 'attributed dementias' in the Latino group, $62.9 \%$ in the African-American group and $63.7 \%$ in the non-Latino White group. A related analysis was restricted to cases given a diagnosis of dementia by the clinical core; functional impairments of any kind were reported by the informant in 207 of these cases, with a reported onset after age 84 in $46.6 \%$ of these 'criterion dementias' in the Latino group, $59.2 \%$ in the African-American group and $72.2 \%$ in the non-Latino White group.

Subtypes of dementia. The distributions of subtypes of dementia are shown in Table 2 for each ethnoracial group. The great majority of dementias, in fairly equal proportions, are diagnosed as Alzheimer's disease in all three ethnoracial groups.

Bias in making diagnoses. The diagnosis of dementia could be spuriously inflated in one or other ethnoracial group by (1) the comorbid presence of depression (either precipitating or simulating symptoms of dementia), or (2) inconsistent application of diagnostic criteria so that 
they are more inclusive (ie broader) in one or other ethnoracial group.

1. Rates of depression, defined as the worst three out of seven severity levels of affective suffering, are highest among non-Latino White dementias $(33.3 \%)$ and Latino dementias $(39 \%)$ and extremely low in the African-American dementia group $(12 \%)$. There is no evident relationship between prevalence rates of dementia and depression.

2. Breadth of diagnosis. The relatively higher rates of dementia among Latino and AfricanAmerican groups compared with non-Latino Whites is consistently evident across concepts of dementia of varying breadth (Fig. 1). For both advanced and borderzone dementias, rates for the Latino and African-American groups are higher than for non-Latino Whites.

Variation with education. There are marked differences in educational achievement among the three ethnoracial groups. More than $40 \%$ of the Latinos have completed less than 5 years of schooling, but almost $90 \%$ of African-Americas and nearly all $(96 \%)$ non-Latino Whites have gone beyond this level. Regression analyses suggest that a large part of the lower rates in non-Latino Whites can be explained by influences associated with better education and higher income levels. Nevertheless, in certain regression analyses but not in others, ethnoracial membership was linked to variation in rates of dementia even after age, education, income and gender were controlled.

\section{Ethnoracial variation in the consequences of dementia}

Ethnoracial comparisons of the functional impairments associated with dementia were carried out on subjects who received a criterion diagnostic evaluation; this procedure was preferred to use of the algorithm because the latter includes confounding measures of functioning. The relative distributions of functional impairments between dementias and non-dementias, whether reported by the subject or by an informant, are similar between the ethnoracial groups. In Latinos, subject reports of two or more functional impairments increased from $50 \%$ in non-dementias to $89 \%$ in dementias; corresponding figures for AfricanAmericans were $46 \%$ and $83 \%$, and for nonLatino Whites $41 \%$ and $85 \%$. It appears that the breadth of concept of diagnosis of dementia as applied in these studies to these three ethnoracial groups has more or less equal implications for functional impairments.

\section{Incidence rates}

New cases of dementia occurring between baseline and first follow-up, an interval averaging 18 months, were identified by two alternative

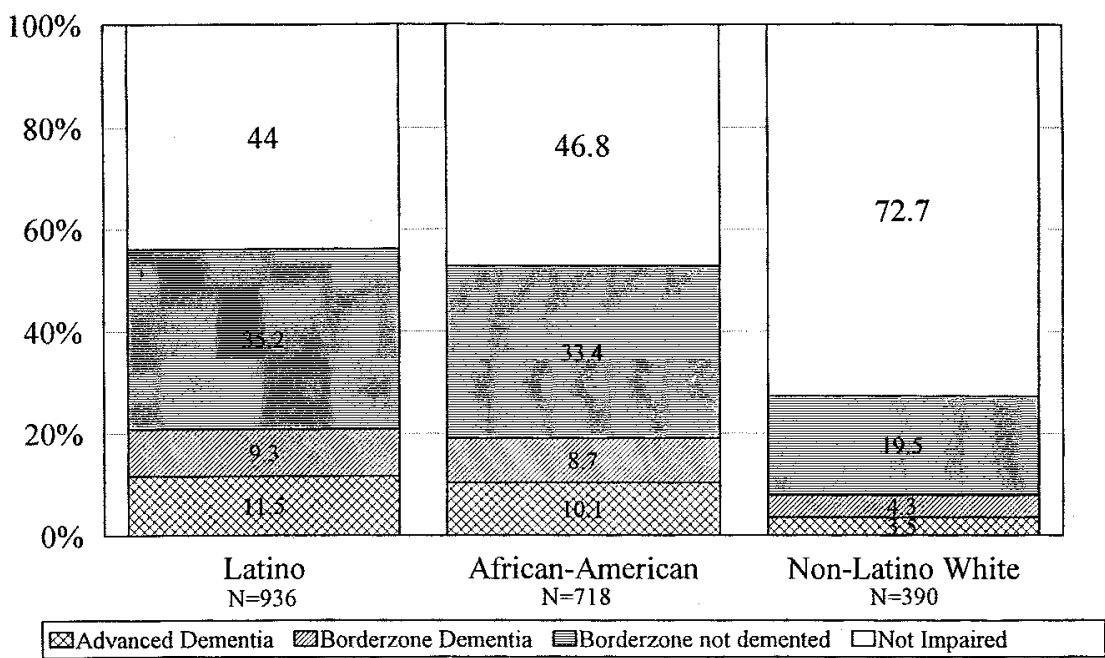

Fig. 1. Rates of dementia by breadth of concept and ethnoracial group. Sample: a sample of 2162 community-residing elders (65 years and older) from the NMAP target area. A weighting procedure was applied to those who received a diagnostic evaluation. Cases from nursing homes and cases designated as paradoxical are excluded from this figure. 
definitions paralleling those for prevalence. (1) According to the first definition, incident cases are those meeting criterion diagnosis at follow-up who had been evaluated and diagnosed as not dementia at baseline. At baseline, all subjects in the first four subsamples, and subjects in any sample who failed the cognitive screening threshold, had been diagnostically evaluated; incidence ratios were the new cases of dementia as a proportion of the cohort survivors diagnostically evaluated at follow-up. Adjustment weights were calculated following the principles presented under prevalence rates and with the same resulting subsample and nonresponse weights combined; however, the weights were applied to both cases (ie dementias) and noncases. (2) The second definition was generated by the algorithm described earlier for classifying cases based on diagnosis, self-report on functioning and the cognitive score; the informant's report on functioning was not used because it was missing at follow-up. This method classified all subjects as cases or non-cases at baseline and follow-up, so that weighting of numerators or denominators was not necessary for calculating incidence rates.

\section{Ethnoracial differences in incidence rates of dementia}

Over the first follow-up period of 18 months, there were 45 incident cases of dementia. Ethnoracial comparisons are given for all ages combined, since numbers in the nine cells formed by the three age and three ethnoracial groups are too small for analysis. Ratios of new cases of diagnosed dementia to number of persons followed up were $8.0 \%$ for Latinos, $8.2 \%$ for African-Americans and $3.1 \%$ for non-Latino Whites. The rates for the Latino and African-American groups are significantly higher $(P<0.01)$ than for the non-Latino Whites. Incidence rates based on the algorithmic case definition are generally consistent with the findings based upon diagnosis: Latinos had higher rates than the non-Latino Whites in every age group. African-Americans had higher incidence rates than did non-Latino Whites in the two younger age groups, but lower rates in those over 85 years old. It should be noted that these incidence rates are based on an average interval of 18 months.

\section{Absolute and relative rates}

Rates of dementia have so far been used to examine relative differences between ethnoracial groups. However, for purposes of estimating illness burden and related service needs in the population groups, absolute rates must also be considered. Whether borderzone dementias are included (a broader concept of dementia) or excluded (a narrower concept) has a substantial effect on calculating absolute rates.

The absolute rates of dementia in each ethnoracial group have been presented earlier and the rates were broken down by breadth of diagnostic concept (Fig. 1). The absolute rates obtained in this study are contrasted with the population studies reviewed in the introduction in Fig. 2. Prevalence

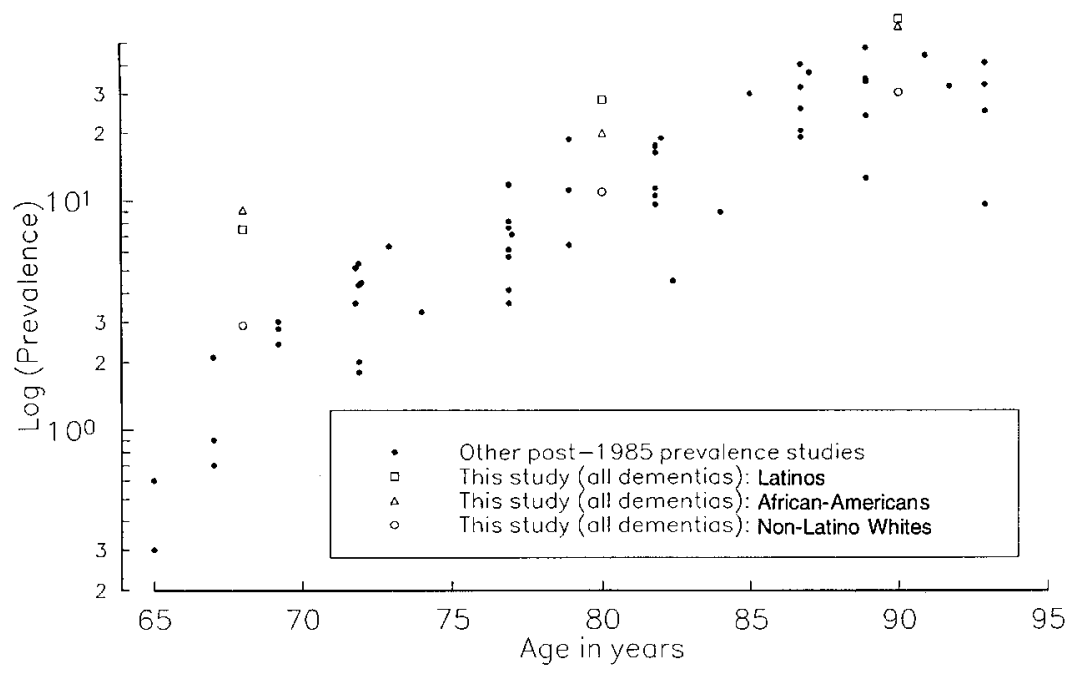

Fig. 2. Age-specific prevalence of dementia in studies since 1985 
rates for Latinos and African-Americans presented here fall above the range of other studies; nonLatino whites in this study are at the higher end of the reviewed range.

In Fig. 3, breadth of diagnostic concept is related, in each ethnoracial group, to the level of functional impairment. Borderzone dementias are distinguished from non-dementias in having greater impairment of functioning, and also from borderzone non-dementias, despite the latter having a range of cognitive impairment equal to the borderzone dementias.
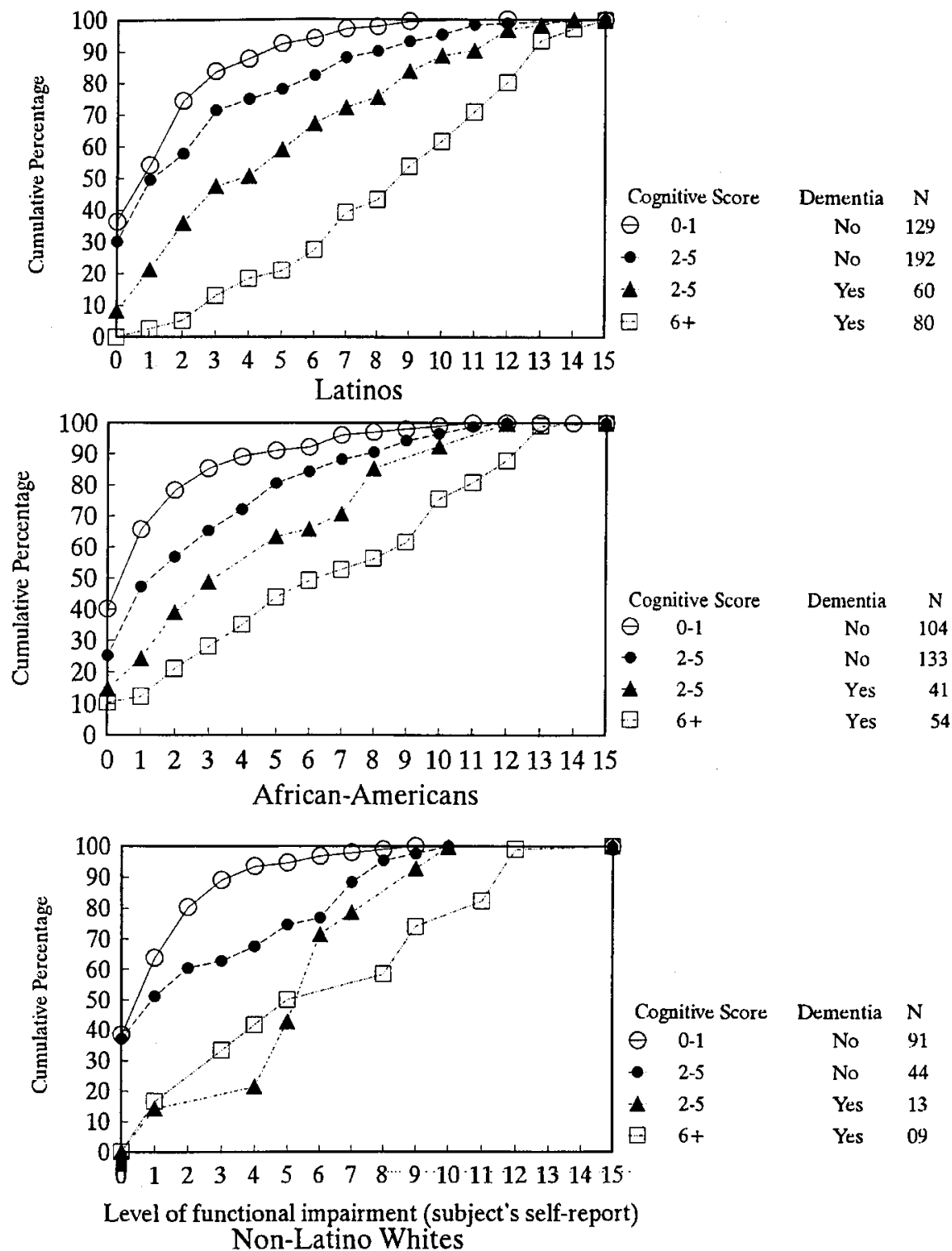

Fig. 3. Functional impairment in dementia. Cumulative percentage distribution of functional impairment scores. Sample: a sample of 2162 community-residing elders (65 years and older) from the NMAP target area. A weighting procedure was applied to those who received a diagnostic evaluation. Cases from nursing homes and cases designated as paradoxical are excluded from this figure 


\section{DISCUSSION}

\section{Limitations of the study data}

The boundaries of the target area were set to include, on the basis of 1980 census data, substantial numbers of each of the three ethnoracial groups. However, in the period of time between the census and the study baseline, changes in the community demographic profile led to a relatively small size of the non-Latino White group. Further reduction of the size of this group in the study resulted from stratified sampling relying on a category of 'Whites' on Medicare lists, who also did not have a Spanish surname. At survey interview, $26 \%$ of this group declared themselves to be Latino.

Given that around a third of those subjects who were approached declined to be interviewed, it is possible that observed group differences in rates of dementia could be due to self-selective influences. Conceivably, dementias were more cooperative in the Latino and African-American groups than among non-Latino Whites. That issue cannot be settled within the data we have at our disposal, but we would have expected any differential cooperation attached to dementia to vary with the severity of dementia. In fact, ethnoracial discrepancies were similar in the borderzone and advanced dementias. In addition, Latino and non-Latino White responders were both significantly younger than non-responders yet significantly different from each other in rates of dementia.

\section{Ethnoracial variation in rates of dementia}

Non-Latino Whites have consistently lower prevalence and incidence rates than the other two ethnoracial groups. These differences are statistically significant where non-Latino Whites of comparable age are contrasted with Latinos and African-Americans.

These ethnoracial comparative results are robust. They are evident whether caseness is defined by diagnosis in a representative subset of the survey sample or by an algorithm applied to all subjects and embracing the best information available from diagnosis, cognitive score, informant report on the subject's competence in daily activities and the subject's own report on their daily activities. The relative rates are also consistent whether only advanced dementias are counted or borderzone dementias are also included.
There is little subtype variation of dementia between ethnoracial groups, removing this possibility as an explanation of ethnoracial variation in rates of dementia. Nor could the biasing or comorbid effects of depression be related to higher dementia rates in the minority groups, since African-Americans showed the lowest proportion of seriously depressed elders,.

The most powerful correlate of the lower rates in non-Latino Whites is their better education. With age and education controlled, the likelihood of being demented is inconsistently related to ethnoracial membership. Possible explanatory influences lying outside the scope of the regression analyses include an earlier age of onset in relatively raising the rates of dementia in Latinos and a higher dementia-related mortality in relatively lowering the rates of dementia in non-Latino Whites.

Elsewhere (Gurland et al., 1995, 1997a), we have posited and detailed three distinct ways in which education might exert an influence on rates of dementia other than through biased testing and diagnosis. In brief, the hypotheses described in these papers are: (1) the selective hypothesiswhere persons developing dementia in late life had reduced cognitive reserves since early childhood leading to discontinuance of education; (2) the associational hypothesis, in which poor education goes hand-in-hand with other mechanisms for inducing dementia (eg malnutrition, exposure to trauma, alcohol abuse, inadequate health care), and (3) the educational hypothesis, in which good and lifelong education builds and maintains cognitive reserves based on robust neurobiological structures and/or behavioral adaptive patterns that compensate for any deteriorative influences bearing upon the brain.

There remains the possibility that these findings are confounded by demographic bias entering into the assessment of cognitive impairment and the diagnosis of dementia. This is a complex issue that we have previously addressed (Gurland et al., 1995, 1997a) but which still remains an open issue requiring a separate paper for further analysis and discussion. Here we point to efforts in this study aimed at minimizing language difficulties; the selection of a screen that was the least biased by demographic factors; and the limiting of biases introduced in screening by keeping the information available to the second stage of classification (diagnosis) independent of information collected in the first stage (screening). Furthermore, the relative ethnoracial differences were replicated 
when the criteria for diagnosis were restricted to advanced, and thus more clearcut dementias. Most of all, we demonstrated that diagnosis carried consistent associations with functional impairments across ethnoracial groups.

\section{Absolute rates of dementia in ethnoracial groups}

The responders in the survey were younger than the non-responders. This implies that the estimates of absolute rates of dementia are probably on the low side.

To be persuaded that a given absolute rate has important implications for illness burden and service needs, it is necessary to see evidence that cases included in the rate suffer from an impairment of quality of life associated with the diagnosis of dementia as applied in the study. The absolute rates of dementia in each ethnoracial group are, naturally, higher if borderzone dementias are included. The latter are validly included with advanced dementias in calculating rates of dementia for each ethnoracial group because these borderzone cases have demonstrably impaired functioning, testimony to the impact of this stage of dementia in diminishing quality of life and increasing demand for personal care services.

\section{ACKNOWLEDGEMENTS}

The late W. Edwards Deming, $\mathrm{PhD}$, designed the sampling plan. The Bureau of Data Management and Strategy of the Health Care Financing Administration provided tape files of Medicare beneficiaries for the North Manhattan Aging Project (NMAP). Peter Cross, MPhil, prepared Fig. 2.

\section{REFERENCES}

American Psychiatric Association (1987) Diagnostic and Statistical Manual of Mental Disorders, 3rd edition, revised American Psychiatric Association, Washington, DC.

American Psychiatric Association (1994) Diagnostic and Statistical Manual of Mental Disorders. DSM-IV American Psychiatric Association, Washington, DC.

Cross, P. and Gurland, B. (1986) The Epidemiology of Dementing Disorders. Report to US Congress Office of Technology Assessment. National Technical Information Service, Washington, DC.

Day, J. C. (1996) Population projections of the United States by age, sex, race, and Hispanic origin: 1995-
2050. US Census. Current Population Reports United States Government Printing Office, Washington, DC, pp. 25-1130.

de la Monte, S. M., Hutchins, G. M. and Moore, G. W. (1989) Racial differences in the etiology of dementia and frequency of Alzheimer lesions in the brain. $J$. Nat. Med. Assoc. 18, 644-652.

Escobar, J. L., Burnam, A., Karno, M., Forsythe, A., Landsverke, J. and Golding, J. M. (1986) Use of the Mini-Mental State Examination (MMSE) in a community population of mixed ethnicity. J. Nerv. Ment. Dis, 174, 607-614.

Folstein, M. F., Bassett, S. S., Anthony, J. C., Romanoski, A. J. and Nestadt, G. R. (1991) Dementia: A case ascertainment in a community survey. J. Gerontol. 46, M132-M138.

Golden, R. R., Teresi, J. A. and Gurland, B. J. (1983) Detection of dementia and depression cases with the Comprehensive Assessment and Referral Evaluation interview schedule. Int. J. Aging Hum. Devel. 16, 242-254.

Golden, R. R., Teresi, J. A. and Gurland, B. J. (1984) Development of indicator scales for the Comprehensive Assessment and Referral Evaluation (CARE) interview schedule. J. Gerontol. 39, 138-146.

Gunner-Svensson, F. and Jensen, K. (1976) Frequency of mental disorder in old age. Acta Psychiatr. Scand. 53, 283-297.

Gurland, B. J. (1981) The borderlands of dementia: The influence of socio cultural characteristics on rates of dementia occurring in the senium. In Clinical Aspects of Alzheimer's Disease and Senile Dementia (N. E. Miller and G. D. Cohen, Eds). Raven Press, New York, 3, pp. 61-84.

Gurland, B. J., Kuriansky, J., Sharpe, L., Simon, R., Stiller, P. and Birkett, P. (1977) The Comprehensive Assessment and Referral Evaluation (CARE). Rationale, development, and reliability. Int. J. Aging Hum. Devel. 81, 9-14.

Gurland, B. J., Wilder, D. E., Cross, P., Teresi, J. and Barrett, V. W. (1992) Screening scales for dementia: Toward reconciliation of conflicting cross-cultural findings. Int. J. Geriatr. Psychiat. 7, 105-113.

Gurland, B. J., Wilder, D. E., Cross, P., Lantigua, R. A., Teresi, J., Barrett, V., Stern, Y. and Mayeux, R. (1995) Relative rates of dementia by multiple case definitions, over two prevalence periods, in three cultural groups. Am. J. Geriatr. Psychiat. 3, 6-20.

Gurland, B., Wilder, D., Lantigua, R., Mayeux, R., Stern, Y., Chen, J., Cross, P. and Killeffer, E. (1997a) Differences in rates of dementia between ethno-racial groups. In Racial and Ethnic Differences in the Health of Older Americans (L. G. Martin and B. J. Soldo, Eds). National Academy Press, Washington, DC, pp. 233-269.

Gurland, B. J., Katz, S. and Chen, J. (1997b) Index of affective suffering: Linking a classification of depressed 
mood to impairment in quality of life. Am. J. Geriatr. Psychiat. 5, 192-210.

Hay, J. W. and Ernst, R. L. (1987) The economic costs of Alzheimer's disease. Am. J. Pub. Health 77, 1169-861.

Heyman, A., Fillenbaum, G., Prosnitz, B., Raiford, K., Burchett, B. and Clark, C. (1991) Estimated prevalence of dementia among elderly black and white community residents. Arch. Neurol. 48, 594-598.

Jorm, A. F., Korten, A. E. and Henderson, A. S. (1987) The prevalence of dementia: A quantitative integration of the literature. Acta Psychiatr. Scand. 76, 465-479.

Katz, S., Ford, A. B., Moskowitz, R. W., Jackson, B. A. and Jaffee, M. W. (1963) Studies of illness in the aged. The index of ADL: A standardized measure of biological and psychosocial function. J. Am. Geriatr. Soc. 185, 914-919.

Kay, D. W. K. (1977) The epidemiology and identification of brain deficit in the elderly. In Cognitive and Emotional Disturbance in the Elderly (C. Eisdorfer and R. O. Friedel, Eds). Year Book Medical Publishers, Chicago, pp. 11-26.

Lawton, M. P. and Brody, E. M. (1969) Assessment of older people: Self maintaining and instrumental activities of daily living. Gerontologist 9, 179-186.

Li, G., Shen, Y. C., Chen, C. H., et al. (1991) A threeyear follow-up study of age-related dementia in an urban area of Beijing. Acta Psychiatr. Scand. 83(2), 99-104.

McKhann, G., Drachman, D., Folstein, M., Katzman, R., Price, D. and Stadlan, E. (1984) Clinical diagnosis of Alzheimer's disease: Report of the NINCDSADRDA Work Group under the auspices of the Department of Health and Human Services Task Force on Alzheimer's Disease. Neurology 34, 939-944.

Murden, R. A., McRae, T. D., Kaner, S. and Bucknam, M. E. (1991) Mini-Mental State Exam scores vary with education in Blacks and Whites. J. Am. Geriatr. Soc. 39, 149-155.

Rice, D. P., Fox, P. J., Max, W., Webber, P. A., Lindeman, D. A., Hauck, W. W. and Segura, E. (1993) The economic burden of Alzheimer's disease care. Health Affairs Summer, 164-176.

Schoenberg, B. S., Anderson, D. W. and Haerer, A. F. (1985) Severe dementia: Prevalence and clinical features in a biracial US population. Arch. Neurol. 42, 740-743.

Stern, Y., Andrews, H., Pittman, J., Sano, M., Tatemichi, T., Lantigua, R. and Mayeux, R. (1992) Diagnosis of dementia in a heterogeneous population: Development of a neuropsychological paradigm-based diagnosis of dementia and quantified correction for the effects of education. Arch. Neurol. 49, 453-460.

Teresi, J. A., Golden, R. R. and Gurland, B. J. (1984) Concurrent and predictive validity of indicator scales developed for the Comprehensive Assessment and Referral Evaluation interview schedule. J. Gerontol. 39(2), 158-165.
Weissman, M. M., Myers, J. K., Tischler, G. L., Holzer, C. E. III, Leaf, P. J., Orvaschel, H. and Brody, J. A. (1985) Psychiatric disorders (DSM-III) and cognitive impairment among the elderly in a US urban community. Acta Psychiatr. Scand. 71, 366-379.

Wilder, D. E., Gurland, B. J., Chen, J., Lantigua, R. A., Katz, S. and Killeffer, E. H. P. (1994) Interpreting subject and informant reports of function in screening for dementia. Int. Geriatr. Psychiat. 9, 827-896.

Wilder, D., Cross, P., Chen, J., Gurland, B. J., Lantigua, R. A., Teresi, J., Bolivar, M. and Encarnación, P. (1995) Operating characteristics of brief screens for dementia in a multicultural population. Am. J. Geriatr. Psychiat. 3, 96-107.

Wimo, A., Ljunggren, G. and Winblad, B. (1997) Costs of dementia and dementia care: A review. Int. J. Geriatr. Psychiat. 12, 841-856.

\section{APPENDIX}

\section{Studies employed in Fig. 2 (prevalence studies)}

Bachman, D. L., Wolf, P. A., Linn, R., Knoefel, J. E., Cobb, J., Belanger, A., D'Agostino, R. B. and White, L. R. (1992) Prevalence of dementia and probable senile dementia of the Alzheimer type in the Framingham study. Neurology 42, 115-119.

Brayne, C. and Calloway, P. (1989) An epidemiological study of dementia in a rural population of elderly woman. Brit. J. Psychiat. 155, 214-219.

Canadian Study of Health and Aging Working Group (1994) Canadian Study of Health and Aging: Study methods and prevalence of dementia. Can. Med. Assoc. J. 150, 899-913.

Coria, F., Gomez de Caso, J. A., Minguez, L., Rodriguez-Artalejo, F. and Claveria, L. E. (1993) Prevalence of age-associated memory impairment and dementia in a rural community. J. Neurol. Neurosurg. Psychiat. 56, 973-976.

Corso, E. A., Campo, G., Triglio, A., Napoli, A., Reggio, A. and Lanaia, F. (1992) Prevalence of moderate and severe Alzheimer's dementia and multi-infarct dementia in the population of southeastern Sicily. Ital. J. Neurol. Sci. 13, 215-219.

D'Alessandro, R., Gallassi, R., Benassi, G., Morreale, A. and Lugaresi, E. (1988) Dementia in subjects over 65 years of age in the Republic of San Marino. Brit. J. Psychiat. 153, 182-186.

Evans, D. A., Funkenstein, H., Albert, M. S., Scherr, P. A., Cook, N. R., Chown, M. J., Hebert, L. E., Hennekens, C. H. and Taylor, J. O. (1989) Prevalence of Alzheimer's disease in a community population of older persons. Higher than previously reported. J. Am. Med. Assoc. 262, 2551-2556.

Fratiglioni, L., Grut, M., Forsell, Y., Viitanen, M., Grafström, M., Holmén, Ericsson, K., Bäckman, L., Ahlbom, A. and Winblad, B. (1991) Prevalence of 
Alzheimer's disease and other dementias in an elderly urban population: Relationship with age, sex, and education. Neurology 41, 1886-1892.

Lobo, A., Saz, P., Dia, J.-L., Marcos, G., Morales, F., Perez, M.-J., Pascual, L.-F., Ventura, T. and Gracia, E. (1989) The epidemiological study of dementia in Zaragoza, Spain. In Psychiatry: A World Perspective (C. N. Stefanis, A. D. Rabavilas and A. D. Soldatos, Eds). Proceedings of the VIII World Congress of Psychiatry, Elsevier Science, Amsterdam and New York, pp. 133-137.

Manubens, J. M., Martinez-L, J. M., Lacruz, F., Maruzabal, J., Larumbe, R., Guarch, C., Urrutia, T., Sarrasqueta, P., Martinez-Lage, P. and Rocca, W. A. (1995) Prevalence of Alzheimer's disease and other dementing disorders in Pamplona, Spain. Neuroepidemiology 14, 155-164.

O’Connor, D. W., Politt, P. A., Hyde, J. B., Fellows, J. L., Miller, N. D., Brook, C. P. B., Reiss, B. B. and Roth, M. (1989) The prevalence of dementia as measured by the Cambridge Mental Disorders of the Elderly Examination. Acta Psychiatr. Scand. 79, 190-198.

Ott, A., Breteler, M. M. B., van Harskamp, F., Claus, J. J., van der Cammen, T. J. M., Grobbee, D. E. and Hofman, A. (1995) Prevalence of Alzheimer's disease and vascular dementia: Association with education. The Rotterdam study. Brit. Med. J. 310, 970-973.
Pfeffer, R. I., Afifi, A. A. and Chance, J. M. (1987) Prevalence of Alzheimer's disease in a retirement community. Am. J. Epidemiol. 125, 420-436.

Rocca, W. A., Bonaiuto, S., Lippi, A., Luciani, P., Turtù, Cavarzeran, F. and Amaducci, L. (1990) Prevalence of clinically diagnosed Alzheimer's disease and other dementing disorders: A door-to-door survey in Appignano, Macerata Province, Italy. Neurology 40, 626-631.

Roelands, M., Wostyn, P., Dom, H. and Baro, F. (1994) The prevalence of dementia in Belgium: A populationbased door-to-door survey in a rural community. Neuroepidemiology 13, 155-161.

Rorsman, B., Hagnell, O. and Lanke, J. (1986) Prevalence and incidence of senile and multi-infarct dementia in the Lundby study: A comparison between the time periods $1947-1957$ and 1957-1972. Neuropsychobiology 15, 122-129.

Skoog, I., Nilsson, L., Palmertz, B., Andreasson, L.-A. and Svanborg, A. (1993) A population-based study of dementia in 85-year-olds. New Engl. J. Med. 326, $153-158$.

Zhang, M. Y., Katzman, R., Salmon, D., et al. (1990) The prevalence of dementia and Alzheimer's disease in Shanghai, China: Impact of age, gender and education. Ann. Neurol. 27(4), 428-437. 